\title{
Modeling Influence of Product Quality and Grower Reputation on Prices in Dutch Flower Auctions
}

\author{
Gregory Yom Din $^{1 *}$, Alexander Slutsky ${ }^{1}$, Yehiel Steinmetz ${ }^{2}$ \\ ${ }^{1}$ Golan Research Institute, University of Haifa, Katzrin, Israel; ${ }^{2}$ Extension Service, Department of Floriculture, Ministry of Agricul- \\ ture, Tel-Aviv, Israel. \\ Email: ${ }^{2}$ rres102@research.haifa.ac.il \\ Received May $7^{\text {th }}, 2011$; revised June $28^{\text {th }}, 2011$; accepted July $16^{\text {th }}, 2011$.
}

\begin{abstract}
The purposes of this study are to examine differences in prices that safari sunset flower growers from Israel receive on the Dutch flower bursa, suggest factors that influence such differences, and examine strength and significance of each factor. We show that price differences between growers can reach 36\% - 47\%. In the regression model price differences are regressed on explanatory variables that include proxies for flower quality and grower reputation. The model explains 58\% - 59\% of the price variability and enables to compare elasticity of price by the studied factors. Subsequent ordered probit analysis confirmed the relevance of the chosen variables and their ability to explain also the growers clustering by received prices. Analysis of marginal effects shows that changes in the probability of belonging to a specific price group of growers are consistent with the regression model results.
\end{abstract}

Keywords: Flower Auction, Safari Sunset, Quality, Reputation, Econometric Model, Simulation

\section{Introduction}

There are significant price differences between growers for the same flower variety and from the same region when agro-climatic conditions, growing technology, and sales opportunities are similar. The purposes of this study are to: a) examine the value and significance of differences in prices received by Israeli growers of safari sunset (Leucadendron "Safari Sunset"), an ornamental branch used in bouquets, on the Aalsmeer Flower Auction (VBA; bursa) in the Netherlands and b) to develop econometric models and determine the strength and significance of factors that may influence these differences.

Price differences are examined taking into account the sources of product differentiation. In the case of perishable horticulture and floriculture commodities traded or auctioned at a single geographical location, the following sources are often examined: a) observable and unobservable attributes associated with quality, fruit size, and homogeneity, such as in fruits and vegetables in India [1], different grades of dates auctioned in Pakistan [2], and citrus fruit in Australia where packing costs differ depending on whether the fruit is to be marketed domestically or internationally [3]; b) the type of market, such as whether cut flowers from Uganda are sold in auctions or direct markets [4], fruits, vegetables, and cut flowers are sold in farmers' markets or grocery stores in Florida [5], tomatoes are sold in supermarkets or traditional markets in developing countries [6], or vegetables and flowers are sold in local stores or in the rural community market in Oklahoma [7]; c) trust-based relationships between buyers and sellers, such as fruit and vegetables marketed to a supermarket supply chain in Honduras [8], or in Japan, where the good reputation of Australian wildflower exporters results in early auction and high prices [9]; and d) market timing, whereby early and late season dates receive good prices while top quality dates sold during mid-season do not [2], and the number of customer transactions varies according to the day of the week [7].

The above findings reflect the non-homogeneity of perishable commodities and market conditions. Goods are never identical, and market conditions such as imperfect information and buyer/seller relationships lead to deviations from the Law of One Price [10].

In this article we study two of the above-mentioned sources of price differences: quality of flowers and reputation of growers, both of which can be influenced by the 
grower. The quality of safari sunset flowers involves recordable and non-recordable attributes. The length of stems is the only recordable attribute that can indicate the quality of this ornamental flower while the hue of the flower is non-recordable (but observable). There are some other observable quality attributes: the shape of bud and foliage, their condition, stalk thickness (diameter), etc. Differences in the color and shape of otherwise similar flowers can impact the selling price [11]. Similar to other agricultural commodities, flower attributes cannot be entirely observed prior to purchase. For example, visually acceptable flowers may have a short vase life, resulting in lower consumer satisfaction [12].

When auction participants have imperfect information, the correlation between price and quality drops and buyers may use the quality of flowers supplied in the past as an indicator of present quality. Thus, if buyers believe a grower's flowers to be of high quality, the grower will enjoy a good reputation and receive a premium price that serves as compensation for his investment in reputation.

Price premiums for firm-specific reputations and quality-signaling and empirical evidence of recordable and non-recordable quality have been studied for various consumer goods ([13-15]). In the study [16], the effects of product quality and grower reputation on prices in horticultural wholesale markets in Australia are examined. The impact of reputation makes sense only in an imperfect information environment [17]. If product attributes are completely observable prior to purchase, then previous production of high quality items would not enter into buyers' evaluations. If information is imperfect and sellers (in auction markets) have a reputation for honesty, then markets react in a positive manner [18].

Detailed data are used to estimate the strength and significance of quality and reputation as factors that influence flower prices. "Quality of product" and "moment of selling" were used to examine prices of carnations in Dutch flower auctions and bunch weight and inspection remarks were found to be significant factors [19]. Thirty features reflecting the visible quality of cut roses from South Africa and the Netherlands were used to model flower prices on the Dutch Flower Auction in Aalsmeer [20]. Reputation was found very important at the Aalsmeer Flower Auction, even when the plants have the same quality code [21]. A price-wedge framework was used to assess the impact of customs and administrative procedures on the quality of cut flowers imported to Japan. It was found that if the existing non-tariff barriers were removed, flowers from growers in other countries would be of higher quality and foreign growers would obtain premium prices [22].

Regression analysis was used to examine the effect of seller reputation on on-line auction prices ([23-25]).
Feedback scores and ratings can be used as proxies for seller reputation [26]. In such sales, reputation has a small but statistically significant positive effect on price [27]. However, reputation indices cannot be applied to Dutch flower auctions as there are important differences between the two: a) Dutch flower auctions last a few seconds while e-auctions last for days; b) multiple sales of items of standard quality take place simultaneously in Dutch flower auctions while unique goods are often sold in e-auctions; and c) seller deception is a major problem in e-auctions but absent in Dutch flower auctions.

In our study primary auction data at the single transaction level is used to analyze price differences between growers. In the first step we test the significance of registered price differences after clustering growers into price groups. We suggest explanatory variables for flower quality and grower reputation, then estimate their influence on price differences using ordinary least squares (OLS) regression analysis. Finally, we examine the relevance of the same quality and reputation variables using an ordered probit model. In this model, we explain probability of belonging of the grower to a specific price group identified in the first step of the analysis.

The unique feature of model design in this study is simulating random pairs of transactions from the same trade days. This approach enables estimating factors that reflect flower quality and grower reputation when the impact of other factors (day of week, part of season, etc.) is controlled or eliminated.

\section{Safari Sunset Industry}

Safari sunset, a Leucadendron belonging to the Proteaceae family, is found mostly in the southern hemisphere. Commercially cultured varieties, obtained through selection and hybridization, require a number of qualities: beauty, long stems, disease resistance, long vase life, and practical reproduction methods [28].

Commercial growing of safari sunset began in the 1970s, but massive sales began only in the 1990s when Israeli farmers began to grow it. The main markets for safari sunset are flower bursas in Europe, especially in the Netherlands. Approximately 22 million safari sunset are sold in Dutch flower bursas yearly; close to $70 \%$ are imported from Israel. Other major exporters are Ecuador, Chile, the Republic of South Africa, and Zimbabwe. Safari sunset branches are ready for sale in winter, therefore, they are gathered in September through April in the northern hemisphere and May through August in the southern [29].

In Israel, the flower industry, particularly ornamentals, combines the country's advantages in climate and knowhow with global marketing facilities such as the European flower bursas [30]. Safari sunset is produced by 
private farmers, partnerships, companies, and kibbutz farms. A typical farm with a packinghouse has a general manager responsible for production, marketing, and sales, and a professional manager responsible for agricultural techniques, irrigation, harvest, and other field works. The Extension Service of the Ministry of Agriculture supports farmers from their first inquiry about new crops and technologies, through the phases of decision-making, planning, and treatment of the crop, to the phases of product marketing and sales. Almost all the production is exported. Growers receive full support in logistics, legal, financial, and informational aspects of export of their production.

\section{Data and Methods}

\subsection{How the Dutch Flower Auction Works}

Dutch flower auctions (bursas) are decreasing sequential auctions. That is, lots of several thousand flowers with stems of the same length are shown to potential buyers. The auction starts at an unreasonably high price per branch. As the clock ticks, prices fall until a buyer bids and acquires the right and obligation to buy the lot or part of it. If there are unsold flowers in the lot, the clock is reset to a high price and the process is repeated. If the clock passes the minimum price, the remaining flowers in the lot are destroyed. The procedure is completely computerized [31-33].

Buyers know the name of the grower whose flowers are in the lots. Thus, the reputation of growers can be important in the pricing of flowers in Dutch bursas.

\subsection{Data}

We use primary not aggregated transaction data in our study. The data set includes day-by-day data of transactions on the VBA for two seasons. Each transaction is identified with a specific grower. Data were collected from eight Israeli growers for the 2006-2007 season and from nine growers (the same eight plus an additional grower) for the 2007-2008 season. Every transaction is described by the ID of the seller (grower) and the buyer, price in Euro cents per stem, length in $\mathrm{cm}$, quality remarks, quantity of branches sold in a single transaction, lot from which the sale originated, and time and date of sale. Data were collected for 5606 transactions during the 2006-2007 season and for 4416 transactions during the 2007-2008 season. In general, flowers from different growers were sold on different days and at different times, and prices were characterized by high volatility. Coefficients of variation were calculated for growers as a ratio of the standard deviation from the average price; such coefficients ranged $36 \%$ - 66\%. Prices were relatively higher at the beginning of the season, before Christmas, and before Valentine's Day. Prices during the first part of the season (September, October) were higher than during the second (November-April), by $54 \%$ in 2006-2007 and 31\% in 2007-2008 (Table 1, Figure 1).

\subsection{Clustering Growers into Price Groups}

Are there significant differences between prices received by growers? To answer this, we used descriptive statistical analysis of price data by season to cluster growers into price groups. The eight or nine growers in each season could be divided into two to four groups. After conducting several preliminary tests, we divided the growers into three groups for each season and examined the sig-

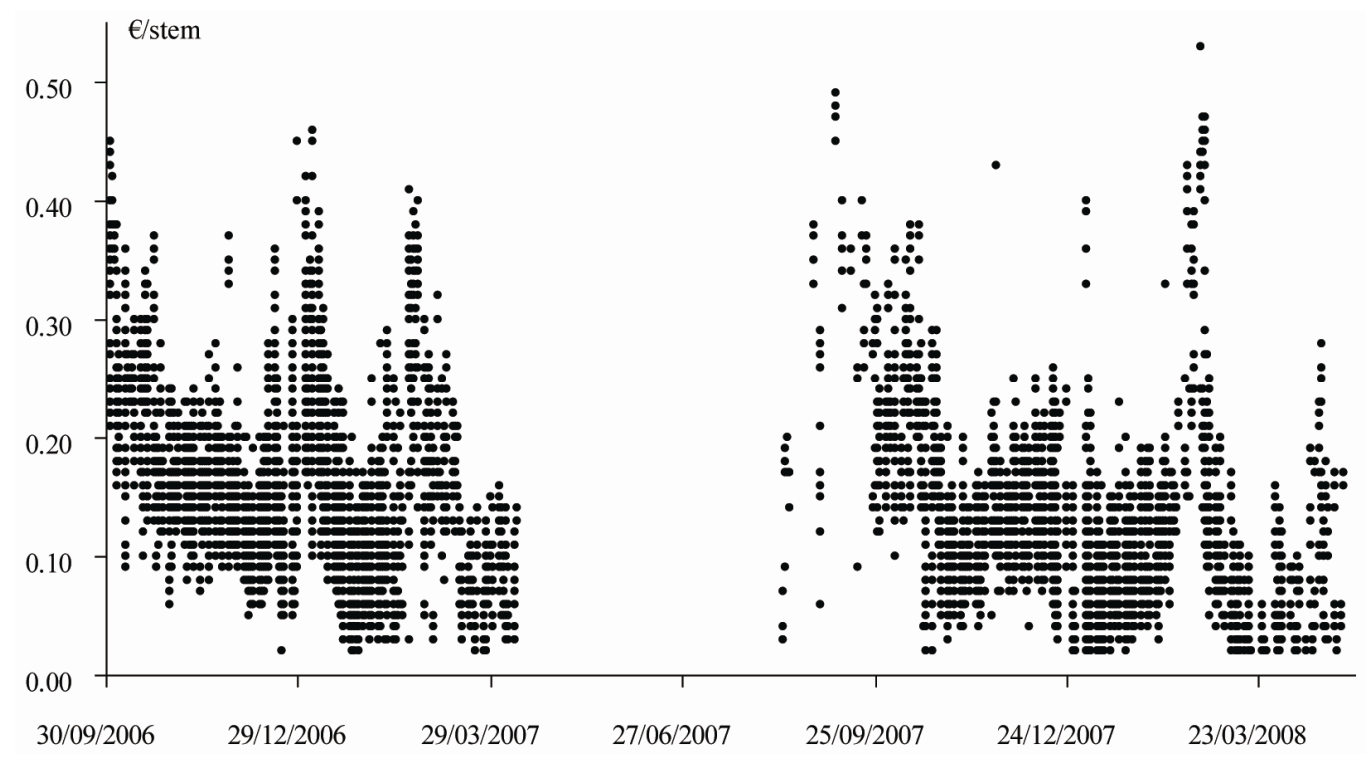

Figure 1. Safari sunset prices received by selected growers. 
Table 1. Price per safari sunset stem in Euro and number of stems sold in the Aalsmeer Flower Auction (Amsterdam), by grower.

\begin{tabular}{|c|c|c|c|c|c|c|c|c|c|}
\hline & \multicolumn{9}{|c|}{ Grower } \\
\hline & 1 & 2 & 3 & 4 & 5 & 6 & 7 & 8 & 9 \\
\hline \multicolumn{10}{|c|}{ Season 2006-2007 } \\
\hline \multicolumn{10}{|c|}{ September-October } \\
\hline Average price & 0.143 & 0.134 & 0.253 & 0.166 & 0.156 & - & - & - & 0.237 \\
\hline Standard Deviation & 0.027 & 0.028 & 0.065 & 0.046 & 0.008 & - & - & - & 0.058 \\
\hline No. transactions & 72 & 20 & 194 & 108 & 10 & - & - & - & 281 \\
\hline \multicolumn{10}{|c|}{ November-April } \\
\hline Average price & 0.117 & 0.137 & 0.150 & 0.138 & 0.154 & - & 0.121 & 0.104 & 0.147 \\
\hline Standard Deviation & 0.061 & 0.071 & 0.065 & 0.066 & 0.071 & - & 0.051 & 0.037 & 0.069 \\
\hline No. transactions & 202 & 435 & 934 & 566 & 667 & - & 697 & 160 & 1,261 \\
\hline Total average & 0.124 & 0.137 & 0.168 & 0.143 & 0.154 & - & 0.121 & 0.104 & 0.164 \\
\hline \multicolumn{10}{|l|}{ Season 2007-08 } \\
\hline \multicolumn{10}{|c|}{ September-October } \\
\hline Average price & 0.121 & - & 0.225 & 0.199 & 0.187 & 0.123 & 0.113 & 0.113 & 0.148 \\
\hline Standard Deviation & 0.073 & - & 0.069 & 0.092 & 0.067 & 0.082 & 0.075 & 0.056 & 0.073 \\
\hline No. transactions & 97 & - & 14 & 170 & 51 & 16 & 804 & 85 & 1,102 \\
\hline \multicolumn{10}{|c|}{ November-April } \\
\hline Average price & 0.091 & 0.092 & 0.110 & 0.100 & 0.132 & 0.098 & - & - & - \\
\hline Standard Deviation & 0.044 & 0.046 & 0.054 & 0.040 & 0.074 & 0.058 & - & - & - \\
\hline No. transactions & 107 & 280 & 706 & 290 & 313 & 381 & - & - & - \\
\hline Total average & 0.105 & 0.092 & 0.112 & 0.137 & 0.14 & 0.099 & 0.113 & 0.113 & 0.148 \\
\hline
\end{tabular}

nificance of price differences between groups. Thus, three paired comparisons of mean group prices could be made. Bonferroni correction is often used in multiple test cases. We used the Bonferroni method that enables widening confidence intervals to reduce an erroneously false rejection of a null hypothesis of zero price differences. In our case, the desired significance level $(\alpha=0.05)$ of the multiple comparisons was divided by 3 (the number of paired comparisons). Then the Bonferroni confidence interval was estimated with the $t$ statistic of $0.05 / 3=$ 0.017 significance level [34].

\subsection{Influence of Flower Quality and Grower Reputation on Price Differences}

To examine the impact of safari sunset quality and grower reputation on price differences, the impact of other factors (e.g., market opportunities) must be taken into account or eliminated. Behavioral factors could be eliminated because the Dutch auction method does not allow buyers to observe the behavior of other buyers. Market opportunity factors include the following: the month and date, whether the transaction was completed during the beginning, middle, or end of the season, whether it took place prior to a holiday, the day of the week of the transaction, the quantity of safari sunset sold on the same day and one or two days earlier, lengths of the flowers sold on the same day, the number and identity of the day's buyers, the value of the transaction, sales of other ornamental branches that could impact the demand for safari sunset, and the exact time the lot was auctioned. To eliminate these factors, we used the model in price differences between two chosen transactions. Only transactions from the same trade day were compared. Further, we assumed these factors were stochastic, and we used a sufficiently large random sample of transaction pairs for model estimation.

To obtain the samples, a transaction was randomly drawn using a uniform distribution. Then another transaction from the same trading day was randomly drawn. These two transactions formed a random pair. After generating a large number of such pairs we used them as a source of data on price differences and explanatory variables. The price difference was defined as the price of the second transaction minus the price of the first transaction, plus a constant 1.5 (to ensure its positive value). Its logarithm served as the dependent variable $L N$ (PriceDifference) of the model (Table 2).

We assumed that most of market opportunity factors 
Table 2. Variables of the price difference model.

\begin{tabular}{ccc}
\hline Variable & $\begin{array}{c}\text { Mathematical } \\
\text { Form }\end{array}$ & $\begin{array}{c}\text { Hypothesized Sign } \\
\text { of the Coefficient }\end{array}$ \\
\hline Dependent_PriceDifference & Logarithm & \\
Independent & & - \\
PartSeason & Dummy & - \\
LengthDifference & Linear & + \\
TransactionQuantityDifference & Linear & - \\
BigBuyersDifference & Linear & + \\
FirstPrice & Linear & - \\
\hline
\end{tabular}

were eliminated because randomly sampled transactions in every pair belonged to the same trading day.

To determine quality, we examined difference in stem length (LengthDifference) and in number of quality remarks made by salespersons as explanatory variables. The latter was found insignificant and thus only LengthDifference remained in the final model. We hypothesized that the coefficient for this variable would be positive. Other quality attributes include color, shape of bud, homogeneity of the flowers in a lot, and vase life. These attributes are not recorded in the bursa database but we assume they are used by buyers to perceive quality. Perceived quality can be regarded as a main dimension of reputation $[35,36]$.

The following proxies for grower reputation are included in the model:

a) Difference in "average quantity of stems per transaction" (TransactionQuantityDifference); we hypothesize that buyers purchase from growers with better reputations indicated by higher prices. Small quantities correspond to high prices, ceteris paribus;

b) Difference in "share of stems of the grower bought by big buyers" (BigBuyersDifference). We hypothesize that large buyers are better experts of grower reputation and that repeated interactions exist between large buyers and growers. Thus, a greater share of stems sold to large buyers suggests a better grower reputation. We defined large buyers as those whose share was greater than $2 \%$ of the total number of purchased safari sunset stems during a specific season. The total number of buyers for each season exceeded 300, only seven of which were defined as large buyers.

The following variables were found insignificant as proxies for grower reputation, and are not included in the final model: part of the lots sold in a single transaction, number of transactions, number of length sizes, and coefficient of variability of the number of transactions during the season.

In addition, we assumed that for every transaction pair the price difference was influenced by the price of the first grower in the transaction, FirstPrice. The higher the first price for a specific transaction pair, the more probable that the price difference for this pair would be positive. If this control variable were not included in the model, the estimated Durbin-Watson statistic would be less than its lower critical value, explained by the bias of a possibly omitted variable. Thus, FirstPrice was added to the model and the coefficient was hypothesized to be negative.

An example of generating random transaction pairs is given in Table 3.

The OLS regression model is written as follows:

$$
\begin{aligned}
& L N(\text { PriceDifference })=\beta+\beta_{1} \text { FirstPrice } \\
& +\beta_{2} \text { LengthDifference } \\
& +\beta_{3} \text { TransactionQuantityDifference } \\
& +\beta_{4} \text { BigBuyersDifference } \\
& +\beta_{5} \text { PartSeason }+u
\end{aligned}
$$

or, in short:

$$
L N(\text { PriceDifference })=\mathbf{x}^{\prime} \boldsymbol{\beta}+u,
$$

where $\mathbf{x}^{\prime}=\left(1, x_{1}, \cdots, x_{5}\right)$ is a vector of five explanatory variables, $\boldsymbol{\beta}=\left(\beta_{0}, \beta_{1}, \cdots, \beta_{5}\right)$ is a vector of the constant term and coefficients of the explanatory variables, and $u$ is a disturbance term that meets the usual assumptions for OLS analysis.

\subsection{Influence of Flower Quality and Grower Reputation on Belonging to a Specific Price Group}

Do the explanatory variables chosen for the OLS model well explain also the clustering of the growers by received prices? To consolidate the analysis we employ these variables in the ordered probit model. We estimate the model for the same random sampling of the bursa data as described in Section 3.4, and for the same five explanatory variables used in the OLS model. We assume that if the variables well explain the probability of a grower belonging to one of the identified price groups, then the answer to the above question will be positive. For this purpose, we gave the dependent variable PriceGroupDifference values of $-2,-1,0,1$, and 2 , when the index number of price group for each of the growers in any transaction pair changed from 1 to 3 . An example of calculating a PriceGroupDifference value is shown in Table 3 (the last column). Ordered probit is appropriate to answer the above question because the dependent variable PriceGroupDifference is measured on an ordinal scale. 
Table 3. Generating random transaction pairs - example from 9 Oct 2006.

\begin{tabular}{|c|c|c|c|c|c|c|}
\hline & \multicolumn{6}{|c|}{ Data } \\
\hline $\begin{array}{l}\text { Randomly Chosen } \\
\text { Transaction }\end{array}$ & Price (Euro/Stem) & Stem Length $(\mathrm{cm})$ & $\begin{array}{l}\text { No. Stems in } \\
\text { Transaction }\end{array}$ & Big Buyers & Share (\%) & Part of Season \\
\hline Transaction No. 1 & 0.19 & 60 & 647 & 40 & & 1 \\
\hline Transaction No. 2 & 0.13 & 70 & 596 & 36 & & 1 \\
\hline \multicolumn{7}{|l|}{ Transaction No. $\cdots$} \\
\hline & \multicolumn{6}{|c|}{ Variable } \\
\hline $\begin{array}{c}\text { Generated Transaction } \\
\text { Pair }\end{array}$ & Price Difference $^{*}$ & First Price & Length Difference & $\begin{array}{l}\text { Transaction Quan- } \\
\text { tity Difference }\end{array}$ & $\begin{array}{c}\text { Big Buyers Share } \\
\text { Difference }\end{array}$ & Part of Season \\
\hline Transaction pair no. 1 & 0.365 & 0.19 & 10 & -51 & -3.5 & 1 \\
\hline \multicolumn{7}{|l|}{ Transaction pair no. $\cdots$} \\
\hline \multicolumn{7}{|c|}{${ }^{*}$ Calculated as $L N(0.13-0.19+1.5)$} \\
\hline
\end{tabular}

The model is written as follows:

$$
\text { PriceDifference }^{*}=\mathbf{x}^{\prime} \boldsymbol{\beta}+u,
$$

where PriceDifference ${ }^{*}$ is an unobserved continuous variable that measures the price difference between the two growers in a transaction pair, $\mathbf{x}^{\prime}$ is a vector of the same explanatory variables as in Equations (1) and (2), $\boldsymbol{\beta}$ is a vector of coefficients of the model, and $u$ is a random normal distributed variable with zero expectation and a standard deviation equal to one unit, a usual assumption in probit analysis.

We find:

PriceGroupDifference $=-2$ if PriceDifference ${ }^{*} \leq \mu_{0}$

PriceGroupDifference $=-1$ if $\mu_{0}<$ PriceDifference ${ }^{*} \leq \mu_{1}$

\section{PriceGroupDifference $=2$ if $\mu_{3}<$ PriceDifference ${ }^{*}$.}

Here, $\mu_{0}<\mu_{1}<\mu_{2}<\mu_{3}$, are unknown parameters, thresholds to be estimated along with $\boldsymbol{\beta}$.

In the ordered probit model, the probability that Price Group Difference takes one of possible values is written as follows:

$\operatorname{Prob}($ PriceGroupDifference $=-2)=\Phi\left(\mu_{0}-\mathbf{x}^{\prime} \boldsymbol{\beta}\right)$,

Prob(PriceGroupDifference $=-1)$

$$
=\Phi\left(\mu_{1}-\mathbf{x}^{\prime} \boldsymbol{\beta}\right)-\Phi\left(\mu_{0}-\mathbf{x}^{\prime} \boldsymbol{\beta}\right),
$$

Prob(PriceGroupDifference $=0)$

$$
=\Phi\left(\mu_{2}-\mathbf{x}^{\prime} \boldsymbol{\beta}\right)-\Phi\left(\mu_{1}-\mathbf{x}^{\prime} \boldsymbol{\beta}\right),
$$

Prob(PriceGroupDifference $=1)$

$$
=\Phi\left(\mu_{3}-\mathbf{x}^{\prime} \boldsymbol{\beta}\right)-\Phi\left(\mu_{2}-\mathbf{x}^{\prime} \boldsymbol{\beta}\right),
$$

$\operatorname{Prob}($ PriceGroupDifference $=2)=1-\Phi\left(\mu_{3}-\mathbf{x}^{\prime} \boldsymbol{\beta}\right)$,

where $\Phi$ represents the standard normal cumulative distribution function.

The marginal effect of the explanatory variables on the probability is calculated separately for different values of the observed variable (formula is given in the Appendix).

Searching for additional evidence of the model specification, we hypothesized that the ordered probit model could confirm the direction and significance of the influence of the explanatory variables (flower quality and grower reputation) on the probability of a grower belonging to a particular price group. This hypothesis is based on the above definition of the observed discrete variable PriceGroupDifference of the probit model using the continuous variable PriceDifference ${ }^{*}$ which is the dependent variable in the OLS model (with log transformation). The direction of the influence depends on whether the sign of the marginal effect is positive or negative, and it differs for different values of PriceGroupDifference. The influence of the other two control variables used in the OLS model (FirstPrice and PartSeason) could not be hypothesized because of the discrete character of the dependent variable PriceGroupDifference. These control variables were kept in the ordered probit model to avoid possible 
specification errors (Table 4).

\section{Results}

Data were analyzed with the SPSS statistical package employing procedures REGRESSION (for OLS regression) and PLUM (for ordered probit analysis). The marginal effects of the ordered probit model were calculated in Microsoft Office Excel.

\subsection{Growers Price Groups}

We began by dividing the growers into three groups and testing the significance of differences between the group mean prices (Figure 2). In the 2006-2007 season, growers 1,7 , and 8 comprised Group 1 with the lowest prices $(0.104-0.124 €)$, growers 2 and 4 comprised Group 2 with mid prices ( $0.125-0.145 €)$, and growers 3 , 5, and 9 comprised Group 3 with the highest prices $(0.146-0.168$ $€)$. In the 2007-2008 season, growers 1,2 , and 6 comprised Group 1 (0.092 - $0.110 €)$, growers 3, 7, and 8 comprised Group $2(0.111-0.129 €)$, and growers 4, 5, and 9 comprised Group $3(0.130-0.148 €)$. The division was relatively stable from season to season, i.e., no grower from Group 1 in the first season moved to Group 3 in the second, or vice versa.

Average prices and confidence intervals for each group of growers in each season are given in Table $\mathbf{5}$. For both seasons and all pairs of groups, confidence intervals do not intersect. Therefore, we conclude that price differences are statistically significant. For Groups 1 and 2 , and Groups 2 and 3, the price was $15 \%-28 \%$ higher in the group with the higher price than in the group with the lower. The price difference between Groups 1 and 3 reached $36 \%$ - $47 \%$.

Clustering growers into price groups obtained in this section was used further in the ordered probit analysis.

\subsection{Influence of Flower Quality and Grower Reputation on Price Differences}

Results of the OLS model are presented in Table 6. For

Table 4. Variables of the ordered probit model.

\begin{tabular}{ccc}
\hline Variable & Mathematical form & $\begin{array}{c}\text { Hypothesized } \\
\text { sign of the } \\
\text { coefficient }\end{array}$ \\
\hline $\begin{array}{c}\text { Dependent- } \\
\text { PriceGroupDifference } \\
\text { Independent }\end{array}$ & $\begin{array}{c}\text { Ordinal variable with } \\
\text { values }-2,-1,0,1,2\end{array}$ \\
PartSeason & Dummy & $?$ \\
LengthDifference & Linear & + \\
TransactionQuantityDifference & Linear & + \\
BigBuyersDifference & Linear & + \\
FirstPrice & Linear & + \\
\hline
\end{tabular}
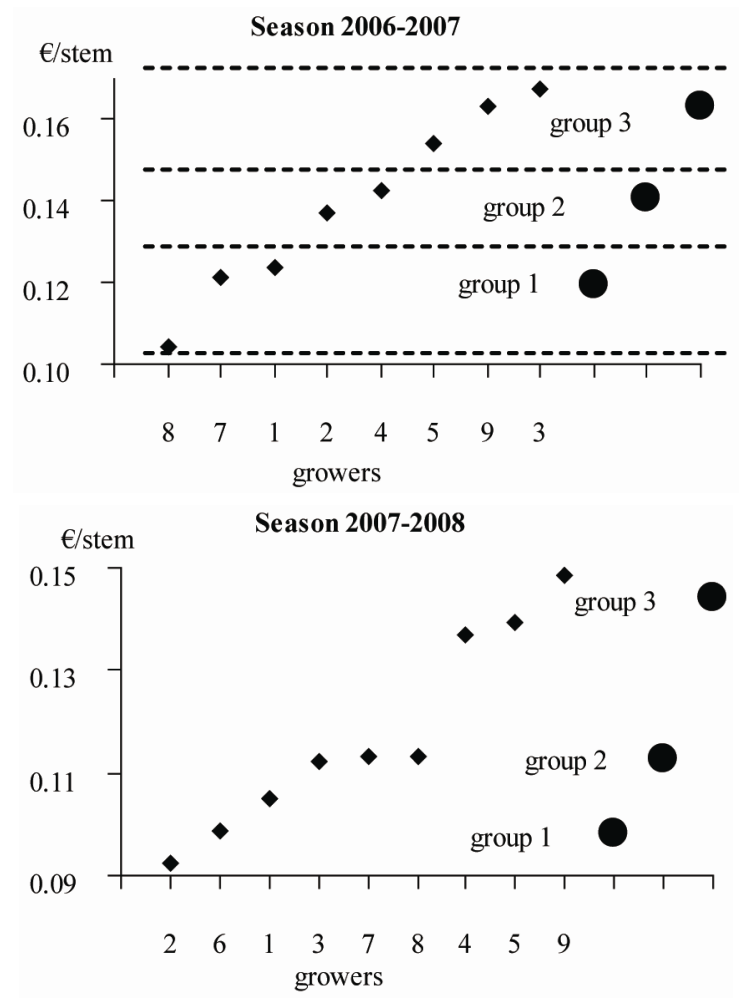

Figure 2. Average prices received by single growers and groups of growers.

Table 5. Dividing the growers into groups by price.

\begin{tabular}{cccc}
\hline \multicolumn{4}{c}{ Group of growers } \\
\hline & 1 & 2 & 3 \\
Season 2006-2007 & \\
Average Price, & 0.119 & 0.141 & 0.163 \\
$\begin{array}{c}\text { Euro/Stem } \\
\text { Standard Deviation }\end{array}$ & 0.054 & 0.066 & 0.074 \\
No. Transactions & 1131 & 1129 & 3346 \\
Confidence Interval, 95\%(0.117, 0.122) & $(0.138,0.143)$ & $(0.161,0.165)$ \\
& Season 2007-2008 & \\
Average price, euro/stem & 0.098 & 0.113 & 0.144 \\
Standard Deviation & 0.056 & 0.066 & 0.075 \\
No. Transactions & 881 & 1609 & 1926 \\
Confidence Interval, 95\% & $(0.095,0.101)$ & $(0.111,0.117)$ & $(0.144,0.152)$ \\
\hline
\end{tabular}

both seasons, all coefficients are significant and their signs confirm the hypothesis presented in Table 2, the last column. The model explains $57 \%-59 \%$ of the variability in price differences. For both seasons, the DurbinWatson statistic is close to 2.12 , indicating that the null hypothesis (i.e., that there is no autocorrelation of firstorder residuals) can not be rejected with a $95 \%$ level of confidence. Since one reason for autocorrelation is in- 
Table 6. Results of the ordinary least squares model, Equation (1).

\begin{tabular}{|c|c|c|c|c|c|c|c|}
\hline \multirow{2}{*}{ Variables and Indices } & \multirow{2}{*}{ Expected Sign- } & \multicolumn{3}{|c|}{ Season 2006-2007 } & \multicolumn{3}{|c|}{ Season 2007-2008 } \\
\hline & & Estimate & Significance & Elasticity & Estimate & Significance & Elasticity \\
\hline FirstPrice & - & -0.5965 & 0.0000 & & -0.6080 & 0.0000 & \\
\hline LengthDifference & + & 0.0007 & 0.0000 & 4.0 & 0.0006 & 0.0000 & 3.9 \\
\hline TransactionQuantityDifference & - & $-1.20 \mathrm{E}-05$ & 0.0003 & -0.5 & $-2.55 \mathrm{E}-05$ & 0.0000 & -0.8 \\
\hline BigBuyersDifference & + & 0.0007 & 0.0000 & 1.9 & 0.0002 & 0.0065 & 0.5 \\
\hline PartSeason & - & -0.0056 & 0.0000 & & -0.0110 & 0.0000 & \\
\hline Constant & & 0.4921 & 0.0000 & & 0.4787 & 0.0000 & \\
\hline$R^{2}$ & & 0.5747 & & & 0.5903 & & \\
\hline Durbin-Watson Statistic & & 2.1283 & & & 2.1252 & & \\
\hline No. of Runs & & 10,000 & & & 10,000 & & \\
\hline
\end{tabular}

correct specification of the model, the results of the Durbin-Watson test indicate that the choice of explanatory variables for our model was appropriate for the data. To be more confident of the unbiasedness of this statistic, the correlation between the residuals and the variable FirstPrice was measured. This variable is the only one measured in level and not in difference (except for the dummy variable PartSeason). The Pearson correlation coefficient was zero for both seasons with a $95 \%$ level of confidence.

The graphical examination of the regression residuals versus the fitted values (skipped here) shows that heteroscedasticity in the regression is not a problem. The positive results of the tests for non-autocorrelation and homoscedasticity confirm the regression estimates.

Coefficients of elasticity, presented in Table 6, are calculated for max - min differences in length, average transaction quantity, and big buyers share as they are shown in the last row of Appendix 2. For example, for season 2006-2007 the elasticity of price by BigBuyersDifference, when this difference receives a maximal value of $27 \%$, is equal 1.9. That is, in this case one percent of increase in Big Buyers share resulted in 1.9 percent increase in price of stem.

\subsection{Influence of Flower Quality and Grower Reputation on Belonging to a Price Group}

The results of the ordered probit model are consistent with those of the OLS model in inferring significance of the studied variables. The coefficients of the three explanatory variables related to flower quality and grower reputation are significant, confirming the relevance of the chosen variables. Each of the control variables, FirstPrice and PartSeason, is not significant in one of the seasons (Table 7).

These results are consistent also with the clustering of the growers by received prices. This can be seen from examination the marginal effects of the explanatory variables that were calculated using Equation (4) from the Appendix. The signs of all the marginal effects confirm our hypothesis regarding the direction of the influence of the explanatory variables (Table 4). For example, for the 2006-2007 season, the probability that PriceGroupDifference would increase by 1 as the result of an increase of one unit in the variable LengthDifference is positive $(0.0009)$. The probability that PriceGroupDifference would increase by 2 for the same increase in LengthDifference is also positive, but much lower (5.798E-06). This conforms to the economic intuition that expects a more probable increase in one rank of price than in two. Regarding the expected directions and values of marginal effects, similar results were obtained for all three explanatory variables of quality and reputation, for all four non-zero values of the dependent variable $(-2,-1,1,2)$, and for both seasons. Total 24 results both for directions and for values of marginal effects:

a) For a random pair of transactions, increase in difference in a stem length (transaction 2 flowers are longer than flowers in transaction 1 results in increased probability that the transaction 2 grower belongs to the price group higher than the price group of the transaction 1 grower.

b) The similar conclusion is true for increase in "share of stems of the grower sold to big buyers" (BigBuyersDifference).

c) On the contrary, increase in "quantity of stems per transaction" (TransactionQuantityDifference) decreases the probability that the transaction 2 grower belongs to the price group higher than the price group of the transaction 1 grower.

\section{Discussion and Conclusions}

Our study confirmed that price differences of safari sunset are significant and relatively large, as much as $36 \%$ - 
Table 7. Results of the ordered probit model, Equations (3) and (4).

\begin{tabular}{|c|c|c|c|c|c|c|c|c|}
\hline \multirow{2}{*}{ Variable } & \multirow{2}{*}{ Estimate } & \multirow{2}{*}{ Significance } & \multicolumn{5}{|c|}{ Marginal Effect (ME) When Dependent Variable Is: } & \multirow{2}{*}{$\begin{array}{c}\text { Sum of } \\
\text { ME }\end{array}$} \\
\hline & & & $=-2$ & $=-1$ & $=0$ & $=1$ & $=2$ & \\
\hline \multicolumn{9}{|c|}{ Season 2006-2007 } \\
\hline FirstPrice & -0.0041 & 0.9840 & $2.1 \mathrm{E}-06$ & 0.0004 & $7.5 \mathrm{E}-05$ & -0.0004 & $-2.9 \mathrm{E}-06$ & 0.0000 \\
\hline LengthDifference & 0.0081 & 0.0000 & $-4.2 \mathrm{E}-06$ & -0.0007 & -0.0001 & 0.0009 & $5.8 \mathrm{E}-06$ & 0.0000 \\
\hline TransactionQuantityDifference & -0.0145 & 0.0000 & $7.5 \mathrm{E}-06$ & 0.0013 & 0.0003 & -0.0016 & $-1.0 \mathrm{E}-05$ & 0.0000 \\
\hline BigBuyersDifference & 0.2322 & 0.0000 & -0.0001 & -0.0208 & -0.0042 & 0.0250 & 0.0002 & 0.0000 \\
\hline PartSeason & 0.1313 & 0.0000 & -0.0001 & -0.0115 & -0.0029 & 0.0144 & 0.0001 & 0.0000 \\
\hline \multicolumn{9}{|c|}{ Season 2007-2008 } \\
\hline FirstPrice & -0.5999 & 0.0003 & 0.0404 & 0.1254 & 0.0013 & -0.1298 & -0.0373 & 0.0000 \\
\hline LengthDifference & 0.0097 & 0.0000 & -0.0007 & -0.0020 & 0.0000 & 0.0021 & 0.0006 & 0.0000 \\
\hline TransactionQuantityDifference & -0.0079 & 0.0000 & 0.0005 & 0.0017 & 0.0000 & -0.0017 & -0.0005 & 0.0000 \\
\hline BigBuyersDifference & 0.1078 & 0.0000 & -0.0073 & -0.0225 & -0.0002 & 0.0233 & 0.0067 & 0.0000 \\
\hline PartSeason & -0.0097 & 0.5533 & 0.0007 & 0.0020 & 0.0000 & -0.0021 & -0.0006 & 0.0000 \\
\hline
\end{tabular}

$47 \%$ between different groups of growers. We focused on flower quality and grower reputation as the sources of these differences. The regression analysis revealed the significance of the explanatory variables chosen to proxy differences in flower quality and grower reputationLengthDifference, TransactionQuantityDifference, and BigBuyersDifference. The significance of BigBuyersDifference has a clear practical implication for growersmajor safari sunset buyers are of primary importance to grower reputation. Elasticity of stem price to each of these variables is considerable in both seasons. It is worth to note that this is elasticity of price to proxies of quality and reputation, and it does not express the impact of expenses required to improve flower quality and grower reputation. Elasticity of price by expenses can differ considerably from that calculated in our study. Additional research is needed for estimating elasticity by expenses.

Our results are similar to those observed in previous studies that used different models. In a price regression model where a subset of grower dummy variables was considered as indication of grower reputation, the effect of reputation was very small [33]. Likewise, in an earlier version of our model, where grower dummy variables were used instead of the proxies TransactionQuantityDifference and BigBuyersDifference, the dummy variables were insignificant. In a study of houseplants supplied by two or three "large" growers to the Aalsmeer Flower Auction, the identity of the grower "seems to have a large impact on the price per unit" for two of three varieties [21].

The importance of product quality and farm reputation for cut-flower prices in European auctions is discussed in studies from developing countries in east Africa [37] and Ethiopia [38,39] both of which entered the cut flower market relatively late. The models presented in our study may be relevant to growers from these regions. As Helmsing and Melese note, the flower auction offers the opportunity to sell globally and build up reputation [39].

Further study of the influence of flower quality and grower reputation is needed because of the implementation of online product representation and screen auctioning at flower auctions. These advancements may increase the influence of reputation on prices. To measure such influence more directly, specific reputation indices of growers could be created.

\section{Acknowledgements}

The study was supported by the Israeli Ministry of Science, grant 3-4764.

\section{REFERENCES}

[1] M. Fafchamps, R. Vargas-Hill and B. Minten, "Quality Control in Non-Staple Food Markets: Evidence from India," Agricultural Economics, Vol. 38, No. 3, 2008, pp. 251-266. doi:10.1111/j.1574-0862.2008.00297.x

[2] A. M. Khushk, A. Memon and K. M. Aujla, "Marketing Channels and Margins of dates in Sindh, Pakistan," Journal of Agricultural Research, Vol. 47, No. 3, 2009, pp. 293-308.

[3] T. H. Spreen, R. L. Kilmer and C. R. Pitta, "Nonhomogeneous Products and the Law of One Price," Agribusiness, Vol. 23, No. 3, 2007, pp. 407-420. doi:10.1002/agr.20130

[4] Y. Esemu and E. Wood, "Innovation and Performance 
Improvement among Exporters in the Uganda Floriculture Industry," In: S. P. Sigué, Ed., Repositioning African Business and Development for the 21st Century, 10th Annual International Conference, Kampala, 19-23 May 2009, pp. 247-258.

[5] J. A. Watson and M. A. Gunderson, "Direct Marketing of Specialty Crops by Producers: A Price-Comparison between Farmers' Markets and Grocery Stores," Southern Agricultural Economics Association, 2010 Annual Meeting, Orlando, 6-9 February 2010. http://purl.umn.edu/56512

[6] B. Minten and T. Reardon, "Food Prices, Quality, and Quality's Pricing in Supermarkets versus Traditional Markets in Developing Countries," Review of Agricultural Economics, Vol. 30, No. 3, 2008, pp. 480-490. doi:10.1111/j.1467-9353.2008.00422.x

[7] J. Biermacher, S. Upson, D. Miller and D. Pittman, "Economic Challenges of Small-Scale Vegetable Production and Retailing In Rural Communities: An Example from Rural Oklahoma," Journal of Food Distribution Research, Vol. 38, No. 3, 2007, pp. 1-13.

[8] J. Blandon, S. Henson and J. Cranfield, "Small-Scale Farmer Participation in New Agri-Food Supply Chains: Case of the Supermarket Supply Chain for Fruit and Vegetables in Honduras," Journal of International Development, Vol. 21, No. 7, 2009, pp. 971-984. doi:10.1002/jid.1490

[9] J. Ekman, J. Eyre and D. Joyce, "Flowers by Sea: Improving Market Access for Australian Wildflowers. Australian Government, Rural Industries Research and Development Corporation," Rural Industries Research and Development Corporation, 2008. https://rirdc.infoservices.com.au/downloads/07-181.pdf

[10] J. C. Batista and G. B. da Silveira Filho, "Trade Costs and Deviations from the Law of One Price," American Journal of Agricultural Economics, Vol. 92, No. 4, 2010, pp. 1011-1023. doi:10.1093/ajae/aaq044

[11] G. Trip, R. B. M. Huirne and J. A. Renkema, "PricePredicting Ability of Farm Managers: Empirical Findings with Flower Producers in the Netherlands," Review of Agricultural Economics, Vol. 22, No. 2, 2000, pp. 464476. doi:10.1111/1058-7195.00033

[12] A. Hoogerwerf, A. E. Simons and M. P. Reinders, "A Systems View on Horticultural Distribution Applied to the Postharvest Chain of Cut Flowers," Agricultural Systems, Vol. 44, No. 2, 1994, pp. 163-180. doi:10.1016/0308-521X(94)90159-D

[13] E. Gerstner, "Do Higher Prices Signal Higher Quality?" Journal of Marketing Research, Vol. 22, No. 2, 1985, pp. 209-215. doi:10.2307/3151366

[14] A. Kirmani and A. R. Rao, "No Pain, No Gain: A Critical Review of the Literature on Signaling Unobserved Product Quality," Journal of Marketing, Vol. 64, No. 2, 2000, pp. 66-79. doi:10.1509/jmkg.64.2.66.18000

[15] H. Schnabel and K. Storchmann, "Prices as Quality Signals: Evidence from the Wine Market," Journal of Agricultural \& Food Industrial Organization, Vol. 8, No. 1,
2010, Article 2.

[16] D. Schoorl and J. E. Holt, "Quality, Reputation and Price in Horticultural Markets," Agricultural Systems, Vol. 13, No. 4, 1984, pp. 191-203. doi:10.1016/0308-521X(84)90073-8

[17] C. Shapiro, "Premiums for High Quality Products as Returns to Reputations," The Quarterly Journal of Economics, Vol. 98, No. 4, 1983, pp. 659-680. doi: $10.2307 / 1881782$

[18] G. Schamel, "Auction Markets for Specialty Food Products with Geographical Indications," Agricultural Economics, Vol. 37, No. 2-3, 2007, pp. 257-264.

[19] I. B. M. M. Kortekaas, "Relation between Quality and Price of Spray Carnations," Acta Horticulturae, Vol. 155, 1984, pp. 193-200.

[20] J. Benninga, "Causes of Variation in the Price of Roses," Acta Horticulturae, Vol. 536, 2000, pp. 471-478.

[21] G. J. van den Berg and B. van der Klaauw, "Structural Empirical Analysis of Dutch Flower Auctions," 2008. http://staff.feweb.vu.nl/bklaauw/laatdruk.htm

[22] L. Liu and C. Yue, "Non-Tariff Barriers to Trade Caused by SPS Measures and Customs Procedures with Product Quality Changes," Journal of Agricultural and Resource Economics, Vol. 34, No. 1, 2009, pp. 196-212.

[23] D. Houser and J. Wooders, "Reputation in Auctions: Theory, and Evidence from eBay," Journal of Economics \& Management Strategy, Vol. 15, No., 2006, pp. 353369.

[24] D. Lucking-Reiley, D. Bryan, N. Prasad and D. Reeves, "Pennies from eBay: The Determinants of Price in Online Auctions," Journal of Industrial Economics, Vol. 55, No. 2, 2007, pp. 223-233. doi:10.1111/j.1467-6451.2007.00309.x

[25] L. Cabral and A. Hortacsu, "The Dynamics of Seller Reputation: Theory and Evidence from eBay," The National Bureau of Economic Research, 2004. http://www.nber.org/papers/w10363

[26] R. G. Hammond, "Comparing Revenue from Auctions and Posted Prices," International Journal of Industrial Organization, Vol. 28, No. 1, 2010, pp. 1-9. doi:10.1016/j.ijindorg.2009.06.002

[27] J. Hou, "Late Bidding and the Auction Price: Evidence from eBay," Journal of Product \& Brand Management, Vol. 16, No. 6, 2007, pp. 422-428. doi: $10.1108 / 10610420710823780$

[28] A. Silber, M. Levi, M. Cohen, N. David, Y. Steinmetz and S. Assouline, "Response of Leucadendron 'Safari Sunset' to Regulated Deficit Irrigation: Effects of Stress Timing on Growth and Yield Quality," Agricultural Water Management, Vol. 87, No. 2, 2007, pp. 162-170. doi:10.1016/j.agwat.2006.06.022

[29] VBN, "VBN Statistiekboek 2006," Vereniging van Bloemenveilingen in Nederland, The Netherlands, 2006.

[30] S. Philosoph-Hadas, S. Droby, I. Rosenberger, Y. Perzelan, S. Salim, I. Shtein and S. Meir, "Sea Transport of Ornamental Branches: Problems and Solutions," Acta 
Horticulturae, Vol. 755, 2007, pp. 267-276.

[31] A. Kambil and E. van Heck, "Reengineering the Dutch Flower Auctions: A Framework for Analyzing Exchange Organizations," Information Systems Research, Vol. 9, No. 1, 1998, pp. 1-19. doi:10.1287/isre.9.1.1

[32] G. J. van den Berg, J. C. van Ours and M. P. Pradhan, "The Declining Price Anomaly in Dutch Rose Auctions," American Economic Review, Vol. 91, No. 4, 2001, pp. 1055-1062. doi:10.1257/aer.91.4.1055

[33] O. R. Koppius, E. van Heck and M. J. J. Wolters, "The Importance of Product Representation Online: Empirical Results and Implications for Electronic Markets," Decision Support Systems, Vol. 38, No. 2, 2004, pp. 161-169. doi:10.1016/S0167-9236(03)00097-6

[34] J. C. Hsu, "Multiple Comparisons. Theory and Methods," Chapman and Hall, London, 1996.

[35] V. P. Rindova, I. O. Williamson, A. P. Petkova and J. M. Sever, "Being Good or Being Known: An Empirical Examination of the Dimensions, Antecedents, and Consequences of Organizational Reputation," Academy of Management Journal, Vol. 48, No. 6, 2005, pp. 1033-1049. doi:10.5465/AMJ.2005.19573108

[36] V. A. Zeithaml, "Consumer Perceptions of Price, Quality, and Value: A Means-End Model and Synthesis of Evidence," The Journal of Marketing, Vol. 52, No. 3, 1988, pp. 2-22. doi:10.2307/1251446

[37] L. Riisgaard, "Global Value Chains, Labor Organization and Private Social Standards," World Development, Vol. 37, No. 2, 2009, pp. 326-340.

[38] M. Gebreeyesus and M. Iizuka, "Discovery of the Flower Industry in Ethiopia: Experimentation and Coordination," Working Paper Series, United Nations University, Maastricht, The Netherlands, 2010.

http://www.merit.unu.edu/publications/wppdf/2010/wp20 10-025.pdf

[39] A. H. J. Helmsing and A. T. Melese, "Endogenisation or Enclave Formation? The Development of the Ethiopian Cut Flower Industry," The Journal of Modern African Studies, Vol. 48, No. 1, 2010, pp. 35-66. doi:10.1017/S0022278X09990218

[40] G. Maddala, "Limited-Dependent and Qualitative Variables in Econometrics," Cambridge University Press, Cambridge, 1983.

[41] W. H. Greene, "Econometric Analysis," 5th Edition, Prentice-Hall, Englewood Cliffs, 2003. 


\section{Appendix 1. Derivation of Marginal Effects in the Ordered Probit Model.}

Marginal effects are the changes in the observable variable PriceGroupDiference that would occur when there are marginal changes in the variables that explain Price-
GroupDiference. Marginal effects are calculated as follows:

$$
\begin{aligned}
& \frac{\partial \operatorname{Prob}(\text { PriceGroupDifference }=-2 \mid \mathbf{x})}{\partial \mathbf{x}}=-\varphi\left(\mu_{0}-\mathbf{x}^{\prime} \boldsymbol{\beta}\right) \boldsymbol{\beta}, \\
& \frac{\partial \operatorname{Prob}(\text { PriceGroupDifference }=-1 \mid \mathbf{x})}{\partial \mathbf{x}}=\left[-\varphi\left(\mu_{1}-\mathbf{x}^{\prime} \boldsymbol{\beta}\right)+\varphi\left(\mu_{0}-\mathbf{x}^{\prime} \boldsymbol{\beta}\right)\right] \boldsymbol{\beta}, \\
& \frac{\partial \operatorname{Prob}(\text { PriceGroupDifference }=0 \mid \mathbf{x})}{\partial \mathbf{x}}=\left[-\varphi\left(\mu_{2}-\mathbf{x}^{\prime} \boldsymbol{\beta}\right)+\varphi\left(\mu_{1}-\mathbf{x}^{\prime} \boldsymbol{\beta}\right)\right] \boldsymbol{\beta} \\
& \frac{\partial \operatorname{Prob}(\text { PriceGroupDifference }=1 \mid \mathbf{x})}{\partial \mathbf{x}}=\left[-\varphi\left(\mu_{3}-\mathbf{x}^{\prime} \boldsymbol{\beta}\right)+\varphi\left(\mu_{2}-\mathbf{x}^{\prime} \boldsymbol{\beta}\right)\right] \boldsymbol{\beta}, \\
& \frac{\partial \operatorname{Prob}(\text { PriceGroupDifference }=2 \mid \mathbf{x})}{\partial \mathbf{x}}=\varphi\left(\mu_{3}-\mathbf{x}^{\prime} \boldsymbol{\beta}\right) \boldsymbol{\beta}
\end{aligned}
$$

For the dummy variable PartSeason, the effect of a discrete change from zero to one for every specific value $k$ of the dependent variable is calculated as the difference between the probabilities of two events: PriceGroupDif- ference equals $k$ for PartSeason $=0$ and for PartSeason $=1$ when all other variables are fixed at their sample means $[40,41]$.

\section{Appendix 2. Statistical Summary of Variables.}

\begin{tabular}{ccccccc}
\hline \multirow{2}{*}{ Grower } & \multicolumn{2}{c}{ Length Range, $\mathrm{cm}$} & \multicolumn{2}{c}{ Average Transaction Quantity } & \multicolumn{2}{c}{ Big Buyers' Share } \\
\cline { 2 - 7 } & $2006-2007$ & $2007-2008$ & $2006-2007$ & $2007-2008$ & $2006-2007$ & $2007-2008$ \\
\hline 1 & $40-80$ & $50-90$ & 596 & 715 & $8.6 \%$ & $23.5 \%$ \\
2 & $40-90$ & $40-90$ & 718 & 689 & $14.0 \%$ & $26.4 \%$ \\
3 & $50-100$ & $50-100$ & 724 & 745 & $34.8 \%$ & $29.0 \%$ \\
4 & $50-90$ & $50-90$ & 647 & 621 & $18.5 \%$ & $21.6 \%$ \\
5 & $55-100$ & $40-100$ & 568 & 476 & $18.8 \%$ & $19.7 \%$ \\
6 & - & $40-100$ & - & 684 & - & $22.0 \%$ \\
7 & $50-90$ & $50-100$ & 857 & 732 & $19.0 \%$ & $25.2 \%$ \\
8 & $60-80$ & $60-80$ & 947 & 785 & $15.5 \%$ & $43.3 \%$ \\
min value & $40-100$ & $40-100$ & 636 & 623 & $25.6 \%$ & $16.6 \%$ \\
max value & 40 & 40 & 568 & 476 & $9 \%$ & $17 \%$ \\
max-min difference & 100 & 100 & 947 & 785 & $35 \%$ & $43 \%$ \\
\hline & 60 & 60 & 379 & 309 & $26 \%$ & $27 \%$ \\
\hline
\end{tabular}

